\title{
Usos midiáticos na constituição de circuitos culturais e
}

\section{comunicacionais populares urbanos}

\section{Yuji Gushiken}

\section{Resumo}

Neste artigo, analisa-se a reinvenção

dos circuitos culturais populares urbanos na mediação direta com as práticas midiáticas contemporâneas. Evidencia-se especificamente 0 uso dos dispositivos tecnológicos de comunicação como modo de constituição das culturas populares urbanas brasileiras na contemporaneidade. Com base no documentário 100\% Favela, produzido no Brasil, enfatiza-se, entre as práticas sociais, a autogestão dos processos culturais e comunicacionais como reinvenção dos modos de existência econômica e simbólica numa favela da cidade de São Paulo. 0 uso dos dispositivos midiáticos e a construção de um discurso de si na cultura da periferia demanda, nos dias hoje, novos modos de escuta social.

\section{Palavras-chave}

Comunicação. Documentário. Culturas populares. Mediações.

\section{Yuji Gushiken I yug@uol.com.br}

Doutor em Comunicação e Cultura pela Universidade Federal do Rio de Janeiro - UFRJ. Professor do Departamento de Comunicação Social e do Mestrado em Estudos de Cultura Contemporânea da Universidade Federal de Mato Grosso - ECCO-UFMT.

Versão final de artigo apresentado na $6^{\text {a }}$ Cumbre Iberoamericana de Comunicadores , Santo Domingo, República Dominicana, 2007 e no Núcleo de Pesquisa Comunicação e Culturas Urbanas no XXX Congresso Brasileiro de Ciências da Comunicação - INTERCOM, 2007.

\section{Introdução: dos efeitos da comunicação ao uso dos meios}

Os primórdios da pesquisa em Comunicação que no caso do Brasil foi em boa parte herança da sociologia empírica americana - buscou durante suas primeiras incursões teóricas produzir respostas sobre os efeitos dos meios de comunicação de massa sobre a opinião e a atitude da audiência. Buscava-se saber através de métodos de pesquisa quantitativos e qualitativos sobre 0 impacto da informação midiática no comportamento das pessoas. Na história das teorias da comunicação (WOLF, 1995; DEFLEUR \& BALL-ROKEACH, 1993), este período de investigação é o que se denominou posteriormente de "teorias de efeitos a curto prazo".

A preocupação com os efeitos, em especial os efeitos a curto prazo, se esgotou desde os primeiros momentos das investigações. E, nos processos de constituição científica e interdisciplinar do campo da comunicação, a pergunta foi invertida: 0 que importava já não era mais o que os meios - os de massa, no caso - faziam com as pessoas, mas o que as pessoas 
faziam com esses meios (WOLF, 1995, p. 63). Este "o que as pessoas faziam com os meios" equivalia mais precisamente a questões então colocadas sobre a produção de sentido e, portanto, sobre a dinâmica do processo comunicacional, que àquela altura deslocava 0 foco: do estudo dos meios para a análise, certamente mais complexa, dos processos sociais.

Simples, mas de revisão importante na história dos estudos em comunicação, a inversão dessa pergunta ainda continua relevante até hoje por ter enfatizado o campo da recepção como parte dinâmica na idéia do que seria o processo de comunicação e de consumo de informações. A hipótese sugerida nessa reavaliação teórica ganha nova relevância na medida em que tecnologias da comunicação, algumas já "tradicionais" e outras mais recentes como a Internet e demais mídias digitais, vêm, como muitos estudiosos apostam, relativizando a superpotencialização dos chamados meios de comunicação massa rádio, TV e mídias impressas - na constituição do imaginário contemporâneo.

Questões importantes a serem colocadas hoje se referem aos usos dos meios de comunicação - não necessariamente pelo aparelho de Estado ou pelas grandes corporações privadas, mas por cidadãos comuns e anônimos, atualizando a proposta então colocada de que o que importa mesmo é o que as pessoas fazem com os meios de comunicação. Nesse ponto, é preciso anotar outro detalhe importante: quando essa noção do que as pessoas fazem com os meios de comunicação emergiu nos estudos teóricos, tratava-se especificamente dos modos como as audiências consumiam, de forma receptiva ou não, mensagens dos meios massivos. No campo teórico, esses usos se referiam à passagem dos estudos dos efeitos a curto prazo para os estudos de efeitos a longo prazo. De qualquer modo, sustentava-se um modelo teórico ainda dominante, propriamente um paradigma científico, cujo foco de interesse - acadêmico, político e mercadológico - eram os efeitos das mensagens sobre as audiências.

Hoje, porém, quando se diz "uso dos meios", é preciso fazer ajustes novamente na perspectiva teórica, já que o próprio objeto se alterou - e muito - na virada dos anos 1980 aos 90 em diante. É que 0 "uso dos meios" já não se refere mais apenas à recepção do conteúdo dos meios de massa - foco que posteriormente deu origem aos chamados "estudos de recepção". Refere-se, isto sim, ao uso dos novos meios de comunicação cujas tecnologias se tornaram mais acessíveis ao consumo de distintas e amplas faixas da população - como se pode observar no Brasil.

Interessa dizer que se percebe uma passagem da comunicação de massa, como modelo midiático hegemônico no século XX, às práticas sociais e midiáticas nem sempre compreendidas no enquadramento disciplinar da chamada "comunicação social", termo que, no Brasil, compreende basicamente os processos instituídos 
da comunicação industrial e as práticas

profissionais socialmente legitimadas: jornalismo, propaganda, relações públicas, radialismo

(atividades no rádio e na televisão) e cinema.

Na década de 1980 já era visível, ainda que não necessariamente de fácil interpretação em sua dimensão socioeconômica e política, a diferença que a entrada em cena das câmeras portáteis de vídeo e do videocassete (VHS) no mercado de tecnologias midiáticas estava fazendo nos modos de se produzir, fazer circular e consumir informações. Desde a década de 1990, outras novas mídias, numa perspectiva otimista do ponto de vista político, vêm desestabilizando e fazendo outras diferenças na concepção de práticas midiáticas: num primeiro momento, a massificação ainda que relativa dos computadores pessoais e, mais recentemente, sua transformação em equipamento móvel no formato notebook com acesso à Internet sem fio; simultaneamente, o desenvolvimento dos aparelhos de telefonia celular, para onde convergem funções audiovisuais, incluindo conexão com Internet.

Não se trata, numa conjuntura de alta visibilidade tecnológica, de fazer apologia da tecnologia, como se ela por si só fosse capaz de promover processos de subjetivação ou emancipação de indivíduos e coletividades. Se a perspectiva é otimista, não necessariamente torna-se ingênua quando se trata de sua inserção no modo de produção capitalista. É a relação do usuário com a tecnologia, uma espécie de agenciamento homem-máquina, que vai apontar como projetos comunicacionais e culturais são construídos numa perspectiva de desenvolvimento social.

Quando se diz "usos dos meios" há, portanto, um movimento que faz um desvio epistemológico no pensamento comunicacional então vigente. A transformação na abordagem teórica, invariavelmente produzida a partir de dados empíricos, evidencia-se no deslocamento dos estudos da comunicação desenvolvidos até então como "ciência do comportamento" para a comunicação como "ciência da cultura", tomando como base modelos de estudos sistematizados por Venicio Artur de Lima (2001). Em outras palavras, há um deslocamento dos estudos sobre os efeitos dos meios e das mensagens para a noção de "usos dos meios" que vai se traduzir nos modos como a cultura passa a interferir como mediação social nos processos comunicacionais.

\section{Comunicação e cultura como práticas de produção de sentido}

No Brasil, distintas práticas sociais, se compreendidas como práticas midiáticas ou comunicacionais, sugerem uma noção desses "usos dos meios". Em especial no âmbito das culturas populares urbanas, memórias das tradições e novas manifestações poéticas vêm sendo constantemente reinventadas na medida em que se articulam e se reproduzem pela repetição dos processos rituais ou pela sua inserção na linguagem do audiovisual. Circuitos 
culturais tendem a sofrer mutações na medida em que se conectam e se capturam nas distintas formas de existência midiática, de modo geral, e distintas formas de existência digital, de forma mais específica, de acordo com as novas - e sempre renovadas - tecnologias da comunicação.

Quando se trata do âmbito do popular no Brasil, a realidade das favelas e das periferias urbanas é representada não raro como foco constituinte do imaginário da violência, segundo versões produzidas via comunicação de massa - seja em roteiros de novelas ou reportagens de telejornal. Em outras palavras, são versões produzidas do "lado de fora" das favelas. 0 imaginário da violência, no entanto, é insistente mesmo quando mudam os narradores do cotidiano urbano. A violência continua sendo narrada, encenada e dramatizada, mas a diferença é que hoje, segundo a noção de "usos dos meios de comunicação", esse imaginário tende a ser construído também com versões do lado de dentro das favelas.

A condição de pobreza certamente reflete a má e mesmo a não-distribuição de renda, e a violência, segundo perspectivas materialistas, tem relação direta com os níveis de exploração econômica e dominação simbólica. Se o popular, não se confundindo com a massa nem com as elites, carrega aquelas evidências de que se constitui no limbo do consumo de bens materiais, criase a idéia, certamente moralista, de que sua correlação direta com o uso das novas tecnologias seria uma espécie de contra-senso das classes trabalhadoras na medida em que seriam vítimas do próprio desejo de consumo.

No entanto, os sentidos que o popular atribui a si mesmo se dão, entre outros modos, pela sua rearticulação constante com distintos modelos de comunicação proporcionados pelas novas tecnologias, e nos dias hoje em especial com as mídias digitais. A passagem de século e de milênio se atualiza como um tempo em que 0 popular se reconstitui numa espécie de popular digital. Trata-se exatamente dos usos midiáticos com que o popular urbano reinventa suas práticas culturais.

Quando a cultura popular se atualiza no enredamento das tecnologias de comunicação, pode-se relacionar essa condição como aquela em que as culturas, hoje, se tornam culturas de fronteira (CANCLINI, 1998, p. 348). Em todo caso, interessa a reconversão de perspectivas sobre o popular na medida que ele se dá em meio à condição de massa, mas ao mesmo tempo inventando modos de sair e ultrapassar essa condição de "maioria silenciosa" (BAUDRILLARD, 1994).

A favela, a partir do momento em que captura para si 0 uso de ferramentas midiáticas, produz um discurso de si. Essa prática discursiva tende a alterar o imaginário urbano, para além dos registros etnográficos, sociológicos e jornalísticos como modelos narrativos e interpretativos de seu modo de vida. A captura das tecnologias midiáticas por parte das camadas populares 
demanda um novo tipo de escuta social. 0 modo como 0 discurso da favela - do popular, portanto - vem sendo produzido é através da auto-gestão de processos comunicacionais, em que os modos expressivos não são apenas as ferramentas da cultura (o corpo, a camiseta, a música, o grafite, enfim, as tradições reinventadas no espaço urbano), mas também a midiatização dos diversos processos culturais. Se há tempos a cultura tem desempenhado ela mesma esta condição de mídia de si, no que o pesquisador brasileiro Luiz Beltrão (2001; 2004) designou de "folkcomunicação", nos dias de hoje os processos de midiatização digital passam a desempenhar e a redimensionar essa função, e a cultura passa a ser a ambiência mediadora de tais práticas comunicacionais.

\section{Circuitos culturais e mediações dos circuitos comunicacionais}

Havia um tempo em que se dizia que uma das funções dos meios de comunicação de massa era dar proeminência a pessoas e coisas, princípio básico da já desgastada abordagem funcionalista. 0 status social seria dado não apenas segundo 0 poder econômico ou político, mas também, nessa era dita informacional, segundo a visibilidade atribuída pela mídia de massa. Acontece que esse princípio de visibilidade de pessoas e coisas passa, nas práticas profissionais da comunicação social, pelo crivo permanente de linhas editoriais (caso do jornalismo) e das determinações empresariais e estratégias de marketing das empresas de comunicação (caso do radialismo).
Por conta desses crivos é que, no imaginário midiático massivo brasileiro, favela e violência são temas em geral fortemente correlacionados.

Acontece ainda que, no imaginário midiático de massa, o estereótipo criado com base no referido princípio de visibilidade gera também séries de constrangimentos no âmbito do popular, principalmente para moradores de favelas e periferias nas cidades brasileiras, quando se trata de inserção social no mundo do trabalho. A própria midiatização do mundo fornece algumas pistas sobre essa questão. Conforme a noção de "usos dos meios", numa espécie de existência midiática que não se refere à comunicação de massa, confere-se uma linha de visibilidade a indivíduos que, de forma mais auto-biográfica, tornam-se produtores de seus próprios discursos e personagens da cidade.

Personagem 1 (MC To): "Quando se pede emprego em São Paulo e se diz que é do Capão Redondo já tem um preconceito. Todo mundo vê 0 Capão com outros olhos. Já não aceitam e falam: 'Do Capão? Ah, tá bom'. E quando você sai, jogam sua ficha dentro do lixo".

Personagem 2 (DJ Ylsão): "Eu trabalhava numa obra. Começamos a exigir cesta básica, registro na carteira, vale-transporte. Começamos a dar de frente com o gerente, com o dono da empresa. Até que 0 'cara' marcou para a gente receber (pagamento), 'nóis' (nós) não fomos, e a polícia estava lá. No outro dia, voltamos lá. A polícia presente, o cara falou que todo mundo que 
'trampava' (trabalhava) na obra foi demitido. 'Ó, tá (está) todo mundo demitido, vocês e toda a obra'. 0 pessoal que não reivindicou nada para não ser demitido, foi mandado embora a mesma coisa. Foi a última vez que trabalhei fichado. Nunca mais. Tudo que faço é por conta. Dou um jeito de fazer eventos, vender camisetas, boné de time (de futebol), rifa. Tem o barzinho, bolão com jogos de futebol e continuar com o grupo (musical Negredo)".

Personagem 3 (DJ Alê): "Tenho 31 anos. Já desisti de procurar emprego porque gasto $\mathrm{R} \$ 10$ por dia para 'rodar', comer na rua, para poder ficar o dia inteiro procurando emprego. E isso eu não tenho. Apesar de fazer muitas coisas, não tenho na carteira o registro que pedem".

0 depoimento dos três personagens acima, habitantes da Favela Godói, no Capão Redondo, periferia da Zona Sul da cidade de São Paulo, está registrado no documentário 100\% Favela, encontrado à venda em loja de departamento de rede varejista com atuação em território brasileiro. Na capa do DVD se lê: "A renda líquida deste DVD será destinada à Associação Periferia Ativa". 0 documentário, com direção de Silvia Bisilliat, foi produzido pelo Projeto $1 \mathrm{da}$ Sul, coordenado pelo DJ Ferréz, e pelo Negredo, grupo de rap composto pelos três personagens da Favela Godói, "quebrada ali no Capão Redondo muito versada pelo Cachorro Louco". 0 Cachorro Louco a que se refere o texto na apresentação do vídeo é Mano Brown, cantor e compositor do grupo Racionais MC, considerado um dos mais conhecidos rappers do Brasil e um dos "padrinhos" artísticos do Negredo.

Em resumo, o documentário, produzido em vídeo digital, narra como o Negredo se organiza enquanto grupo musical, na medida em que pratica um híbrido de ativismo e empreendedorismo cultural comunitário na periferia de São Paulo. A narrativa do documentário, conduzida principalmente por DJ Ylsão, tem como foco a produção do show de lançamento do CD do grupo. Animado pela idéia de autogestão comunitária, o grupo se utiliza da produção simultânea do documentário em DVD para mostrar como se processam, na favela, as relações do grupo de músicos e animadores culturais com o entorno social em que vivem: familiares, moradores, outros artistas, empresários, traficantes de drogas, criminosos, Igreja e polícia.

Produzido com câmera digital em mãos, num realismo típico dos documentários, o filme exibe, em imagens por vezes trêmulas, as ruas estreitas e tortuosas da periferia da Zona Sul paulistana. Apesar dos estranhamentos da cidade grande, que sugere uma certa fragilidade da existência individual na maior metrópole sulamericana, o roteiro enfatiza uma certa potência da organização comunitária na produção de um "discurso de si" em meio a uma condição massiva do cotidiano na periferia. A violência urbana, em especial o massacre de 111 presos ocorrido na 
Casa de Detenção do Carandiru, em 2 de outubro de 1992 na cidade de São Paulo, com repercussão internacional, foi o que gerou, no grupo, a "necessidade de se expressar" sobre a realidade social dos habitantes da periferia da metrópole, onde a violência é uma instalação cotidiana.

Antes do processo de midiatização, porém, o que há é a produção cultural, um saber-fazer comum e de domínio público, no caso o hip hop, como "modo de expressão" coletiva. 0 hip hop, em especial o rap, como se sabe, tem sido um dos elementos da cultura popular urbana que, no Brasil, vem formando ambiências socioculturais em que segmentos da juventude das periferias das cidades produzem não apenas seus modos de existência simbólica, mas também suas condições de existência econômica. 0 que seria uma hipótese ganha evidência nas imagens do documentário 100\% Favela, produzido pelos próprios personagens e narradores do Capão Redondo. Na produção do show de gravação do $\mathrm{CD}$, registrado em DVD, moradores montam barracas de comida e bebida na rua, técnicos de sonorização cuidam dos detalhes acústicos, operários montam a estrutura do palco, um DJ faz 0 teste de som entre parafernálias de equipamentos, um grupo de grafiteiros atribui formas e cores a um portão de garagem com a devida autorização da moradora da casa.

0 show, organizado com participação comunitária, acontece numa das ruas da favela. Nas imagens diurnas, ainda durante a preparação do evento cultural, um certo anseio transparece numa trupe de jovens que, sentados na calçada, parecem aguardar a hora do show logo mais à noite. Nas imagens noturnas, a rua, então lugar de passagem de automóveis e pedestres, torna-se, naquela ocasião festiva, espaço de uma sociabilidade reinventada através da produção cultural. A rua do evento, nas imagens do vídeo, ganha ares de uma "rua subjetiva", com o trânsito de seus moradores, de outras gentes de outros bairros, movimentações da multidão, gestualidades de coreografias coletivas, cores, sons, odores, sabores.

Quando se trata de cultura popular urbana no Brasil, as práticas sociais evidenciam como a cultura, no mais das vezes, tende a ser produzida também a partir de práticas do mundo do trabalho, até porque a própria arquitetura da favela é daquelas práticas de linguagem que se evidenciam na paisagem urbana como um saber-fazer de domínio público, uma tecnologia que migra dos grandes empreendimentos de construção civil e se aplica na reinvenção da sobrevivência nas cidades brasileiras.

Além da arquitetura, este também é o caso do grafite, elemento fundamental na ambiência do hip hop. A prática poética dos grafiteiros se dá com latas de spray, compressores e pistolas de jato de tinta, ferramentas de trabalho cujo manuseio também não é segredo, porque são as mesmas ferramentas usadas em oficinas mecânicas, obras de construção civil, funilarias e 
oficinas de pintura. As imagens que surgem desse manuseio de ferramentas de trabalho também não são segredo, pois são imagens correntes no imaginário urbano: vêem-se, nos grafites, automóveis, cantores de música pop e ícones religiosos como a imagem de Jesus Cristo. Como se percebe, são imagens do mundo do trabalho e do cotidiano produzidas na e pela favela, na medida em que se faz uso da mídia e da cultura como modo de produção simbólica.

No entanto, o imaginário da violência persiste quando, durante a produção do evento, 0 documentário registra uma patrulha da Polícia Militar de São Paulo fazendo batida numa casa da favela. Crianças e adultos, entre curiosos e apreensivos, assistem à cena em que policiais armados rendem hipotéticos suspeitos de algum crime, colocando-os de frente para a parede e com as mãos ao alto. Na hora do show, seguranças do evento, que hipoteticamente são moradores do próprio bairro, revistam participantes da festa ao entrarem no recinto de espetáculo de lançamento do CD.

Vários grupos de rap são convidados a participar do show, numa espécie de parceria para a realização do evento. Configura-se um circuito cultural em torno do hip hop como ambiência agregadora da coletividade dos moradores de periferia - daquele bairro e de muitos outros. 0 rapper Mano Brown, num dos trechos do documentário, lembra que o discurso da periferia é o do individualismo, do "cada um por si", mas que no hip hop se diz "nós", sugerindo no vocabulário usado uma dimensão do trabalho coletivo traduzido em palavras de ordem como "união" e "respeito".

0 caso da Favela Godói, na Zona Sul paulistana, vem se tornando um entre muitos exemplos da mediação das práticas culturais no campo do audiovisual. ${ }^{1}$ A produção do documentário atualiza um modo de autogestão da comunicação e da cultura que possibilita tornar pública uma pequena história urbana em sua singularidade. Essas narrativas subjetivas atualizam o modo de a comunidade produzir uma escritura no mundo, a partir do momento em que a favela se torna uma favela digital. Assim, através de distintos usos midiáticos, o que parece mesmo estar em jogo é a supremacia dos meios de comunicação de massa como únicas fontes na formação do imaginário contemporâneo. Entram em cena as coletividades e suas práticas culturais e midiáticas, com desejo de se tornar, elas próprias, sujeitos da comunicação, da cultura e, portanto, da história.

Deve-se enfatizar que a aposta numa autogestão da cultura e da comunicação tem sido também uma aposta num sujeito pensante, racional, já não mais o sujeito atomizado e supostamente passivo das primeiras incursões teóricas da mass communication research americana. A partir 
da noção de "usos dos meios", trata-se agora não apenas da idealização, mas da atualização, de um sujeito gestor de outros saberes, outras epistemes, outras poéticas, na relação com sua alteridade social, na relação com as novas tecnologias de comunicação e nas relações consigo mesmo.

Já havia aqui a emergência de um novo pensamento comunicacional a partir da invenção de distintas práticas sociais que se traduzem como práticas expressivas e comunicacionais. De figurante a personagem principal no enredo da vida cotidiana, tal qual em filme de cinema, a imaginação criadora do cidadão comum é que também potencializa a construção de modos de fugir deste - por vezes conformado e tedioso mundo de hoje. Mas, para uma atual angústia, talvez haja um novo entusiasmo. Uma vez inventados os meios, e os modos de usá-los, resta promover a fuga.

\section{Pensamento comunicacional nas práticas sociais urbanas}

A poética produzida nos movimentos urbanos brasileiros, que nem sempre se enquadram no que chamam de "novos movimentos sociais", sugere que, quando se trata de questões comunicacionais, pode-se considerar que práticas artísticas e culturais emergem no cotidiano desses grupos tendo como base um modo de fazer circular informações e idéias. Há, certamente, um processo de diferenciação entre os dispositivos poéticos e comunicacionais, principalmente pelo fato de que arte não necessariamente busca comunicar um sentido comum ou unívoco.

Acontece, porém, que, se considerarmos a comunicação em sua força paradigmática na constituição da cultura contemporânea, podese perceber como, nos movimentos sociais e culturais, o pensamento comunicacional emerge ao modo de práticas de produção de linguagem em gêneros variados, que vão das artes eruditas ao artesanato, da linguagem oral à linguagem visual, quando não do cruzamento entre elas. Essas práticas sociais não são exatamente 0 que se entende como as práticas profissionais da comunicação social - jornalismo, propaganda, relações públicas e radialismo. Mas são modos - ou modelos - de produção e circulação de informação que, mais que serem alternativos aos chamados meios industriais da comunicação de massa, são discursos transversais aos sistemas de informação hegemônicos.

Quando se trata de estudos em comunicação, convém lançar mão de perspectivas teóricas que compreendam tais práticas poéticas, invariavelmente práticas midiáticas, como temas próprios desse campo do saber. Portanto, trata-se de considerar o fenômeno contemporâneo em que distintas práticas sociais e culturais vêm se constituindo como forma de produzir mediações e intervenções no pensamento comunicacional brasileiro e, por extensão, latino-americano.

Deve-se considerar, no plano teórico, a passagem histórica dos estudos dos efeitos para o uso dos 
meios tecnológicos na produção, circulação e consumo de informações nos dias de hoje. No plano empírico, visualizam-se modos de invenção de distintos circuitos comunicacionais em diferentes redes de movimentos sociais. 0 que se vê, no âmbito da cultura popular urbana, é a criação e a invenção de oficinas midiáticas, em que se evidenciam práticas artísticas e culturais como a produção de ambientes em que circulam as informações na produção dos discursos relativos à cidadania e à subjetividade.

Além das brechas das mediações (MARTINBARBERO, 1997), outras duas abordagens teóricas da Comunicação permitem conceber práticas poéticas como práticas ditas comunicacionais: a folkcomunicação, do brasileiro Luiz Beltrão (2001; 2004), e a visão ritual da Comunicação, do americano James Carey (1992). Nesses dois modelos teóricos concebem-se práticas sociais como práticas comunicacionais, na medida em que as consideram simultaneamente como práticas de produção de sentido.

Da abordagem teórica de Beltrão (2001; 2004), interessam os modos como as mediações da cultura popular são concebidas como veiculadoras de informações. Da abordagem teórica de Carey (1992), interessam os rituais de vinculação social para além dos antigos difusionismos culturais e comunicacionais. Entre Beltrão e Carey, o que há é a ampliação do campo comunicacional que passa a compreender, debaixo de seu guarda- chuva teórico, práticas sociais compreendidas como produtoras de sentido.

A partir dessas perspectivas teóricas, concebemse práticas expressivas da cultura e o uso das tecnologias midáticas como modos de invenção de novas práticas comunicacionais que atravessam a condição molar da chamada comunicação de massa. Desde a década de 1980 se observa, nos estudos em Comunicação, a emergência e visibilidade da tecnologia audiovisual como ferramenta expressiva de distintos grupos sociais no Brasil e na América Latina.

No entanto, mais que a visibilidade atualizada pela tecnologia, o que tem sido próprio desta "era digital", interessa mais propriamente 0 agenciamento em que se cruzam as diferentes formas de existência na relação homem-máquina. Ou seja, a visibilidade de distintos segmentos sociais, no Brasil, passa hoje pelo uso que se faz de tradicionais formas de expressão cultural na hibridação com as mais recentes tecnologias de registro e comunicação digital.

Segundo o espanhol-colombiano Jesús MartinBarbero (1997), a configuração das identidades culturais teria, como um de seus atuais registros, 0 fato de que as novas tecnologias seriam 0 ponto culminante de uma certa "operação antropológica". Essa operação reativaria a lógica evolucionista que converte o Outro em "atrasado". Assim, como sustenta 0 autor, 0 que constitui a identidade, no caso latinoamericano, é o que nos falta, "o que nos constitui 
é a carência, e do que carecemos é a tecnologia produzida pelos países centrais, o que vai nos permitir o salto para a modernidade". (p. 254)

Portanto, a cultura contemporânea em países latino-americanos como o Brasil vem sendo reinventada em condições socioeconômicas que transitam entre manutenção de tradições e experimentações de linguagem com novas tecnologias. Considera-se, portanto, nessa situação, não a produção, mas o consumo de novas tecnologias como instância em que se cria um sentido político no qual se articula a relação entre produção de saber, produção econômica e novas relações de poder na sociedade brasileira. Cabe redefinir, quando se trata das questões entre comunicação e política, as nuances em que as circunstâncias agregam a produção de bens simbólicos com a produção de riqueza no que os cientistas sociais Antonio Negri e Maurizio Lazzarato (2001) chamam de "trabalho imaterial".

0 chamado trabalho imaterial, segundo Negri e Lazzarato (2001, p. 47), se relaciona com 0 processo social que se torna processo econômico. E o que é mais social é exatamente a linguagem, a comunicação. A relação entre comunicação e desenvolvimento, portanto, pode traduzir-se numa outra fórmula: comunicação "é" desenvolvimento, a partir da consideração, hoje fundamental para as camadas populares, de que distintas formas de produção de saber, incluindo os saberes comunicacionais, ganham outro estatuto, certamente numa perspectiva afirmativa, na emergência de distintas formas de subjetivação e emancipação coletivas na vida contemporânea.

Para além dos produtos da chamada indústria cultural, que são resultado da moderna e não raro enfadonha cultura de massa, interessa analisar a emergência singular de distintas formas de produção cultural, propriamente laboratórios sociais, em que saberes midiáticos são construídos em condições economicamente adversas em países como o Brasil e, de modo geral, na América Latina. Para além do modelo funcional da comunicação de massa, em que se concebe um imaginário midiático comum e supostamente homogêneo, deve-se perceber na profusão das práticas midiáticas contemporâneas que o "em comum", nos dias de hoje, insiste em ser concebido em sua multiplicidade.

Essa multiplicidade do "em comum" se dá certamente no uso dos meios de comunicação, ou seja, no uso das tecnologias que constitui processos de midiatização das culturas populares urbanas. No entanto, a singularidade desses processos de midiatização é constituída não em seu caráter de "veiculação" de informações, que logo reconstituiria o velho modelo difusor da comunicação. Antes, tal singularidade se dá no que o professor brasileiro Muniz Sodré (2002, p. 234) designa como "vinculação", que compreende "práticas estratégicas de promoção ou manutenção do vínculo social, empreendidas por ações comunitaristas ou coletivas, animação 
cultural, atividade sindical, diálogos etc." Assim, segundo 0 autor, isso se diferencia da pura relação produzida pela mídia autonomizada, na medida em que a vinculação se pauta por formas diversas de reciprocidade comunicacional afetiva e dialógica - entre os indivíduos.

A atribuição de valor aos saberes produzidos fora dos circuitos culturais socialmente legitimados supõe colocar em cena distintos modos como as práticas culturais subalternas se afirmam quando se cogita a interface entre cultura e midiatização do mundo contemporâneo. Nesse caso, a relação entre comunicação e desenvolvimento passa não mais pela legitimação de uma suposta visibilidade de grupos ou classes sociais nos meios de comunicação de massa, pelo volume de informações consumidas pela massa populacional ou pela perspectiva que considera a comunicação como ferramenta de difusão de valores socialmente homogêneos.

Ao contrário, a perspectiva dos "usos midiáticos" aponta para outros aspectos, o que inclui os modos como distintos atores sociais reinventam circuitos comunicacionais e culturais como estratégias de produção, circulação e consumo de outras informações, outras idéias, outros saberes, outras epistemes, no mundo contemporâneo. Quando se trata de comunicação, certamente que esses processos de produção de subjetividade demandam novos modos de escuta social.

\section{Referências}

BAUDRILLARD, Jean. À sombra das maiorias silenciosas: 0 fim do social e 0 surgimento das massas. Tradução: Suely Bastos. São Paulo: Brasiliense, 1994.

BELTRÃO, Luiz. Folkcomunicação: teoria e Metodologia. São Bernardo do Campo: Umesp, 2004.

Folkcomunicação: um estudo dos agentes e dos meios populares de informação de fatos e expressão de idéias. Porto Alegre: Edipucrs, 2001.

BRANDÃ0, Ludmila de Lima. A casa subjetiva: matéria, afectos e espaços domésticos. São Paulo: Perspectiva; Cuiabá: Secretaria de Estado de Cultura de Mato Grosso, 2002.

CANCLINI, Néstor Garcia. Consumidores e cidadãos: conflitos multiculturais da globalização. Rio de Janeiro: UFRJ, 1995.

Culturas híbridas: estratégias para entrar e sair da modernidade. Tradução: Ana Regina Lessa e Heloísa Pezza Cintrão. São Paulo: Edusp, 1998.

CANEVACCI, Massimo. Sincretismos: uma exploração das hibridações culturais. Tradução: Roberta Barni. São Paulo: Studio Nobel; Instituto Cultural ÍtaloBrasileiro, 1996.

CAREY, James W. Communication as culture: essays on media and society. New York: Routledge, 1992.

CASTELLS, Manuel. A sociedade em rede, a era da informação: economia, sociedade e cultura. Vol. 1. São Paulo: Paz e Terra, 2002.

DeFLEUR, MELVIN \& BALL-ROKEACH, Sandra. Teorias da comunicação de massa. Rio de Janeiro: Jorge Zahar, 1993.

DOWNING, Johh. D. H. Mídia radical: rebeldia nas comunicações e movimentos sociais. Tradução: Silvana Vieira. São Paulo: Senac São Paulo, 2002. 
GROPP0, Luís Antonio. Juventude: ensaios sobre

Sociologia e História das juventudes modernas. Rio de Janeiro: Difel, 2000.

GUATTARI, Félix; ROLNIK, Sueli. Micropolítica: cartografias do desejo. Petrópolis: Vozes, 1996.

GUSHIKEN, Yuji. Dialogismo: emergência do pensamento latino-zmericano em comunicação.

Comunicação, Mídia e Consumo, São Paulo, vol. 3. n. 8, p. 73-91, 2006.

LAZZARAT0, Maurizio \& NEGRI, Antonio. Trabalho imaterial: formas de vida e produção de subjetividade. Rio de Janeiro: DP\&A, 2001.

LIMA, Venício Artur de. Mídia: teoria e política. São Paulo: Fundação Perseu Abramo, 2001.

MARTIN-BARBER0, Jesús. Dos meios às mediações: comunicação, cultura e hegemonia. Tradução: Ronald Polito e Sérgio Alcides. Rio de Janeiro: UFRJ, 1997.

MATTELART, Armand. Comunicação-mundo: história das idéias e das estratégias. Petrópolis: Vozes, 1996.

NICHOLS, Bill. Introdução ao documentário. São Paulo: Papirus, 2005.

SILVA, Juremir Machado da. As tecnologias do imaginário. Porto Alegre: Sulina, 2003.

SODRÉ, Muniz. Antropológica do espelho: uma teoria da comunicação linear e em rede. Petrópolis: Vozes, 2002.

TUCHERMAN, Ieda. Breve história do corpo e de seus monstros. Lisboa: Vega, 1999.

WARD, Paul. Documentary: the margins of reality. London: Wallflower, 2005.

WILLIAMS, Raymond. Cultura. São Paulo: Paz e Terra, 2000.

WOLF, Mauro. Teorias da comunicação. Lisboa: Presença, 1995.

\section{Vídeo}

100\% FAVELA. Produção do Projeto 1 da Sul (DJ Ferrez) e Negredo Produções. Direção: Silvia Bisilliat. São Paulo: Atração Fonográfica, 2006. 1 DVD (205 min): NTSC, son., color. Legendado. Port., Esp., Ing. 
Media uses in the constitution of popular urban cultural communicative circuits

\section{Usos mediáticos en la constitución de circuitos culturales y comunicacionales populares urbanos}

\section{Resumen}

Abstract

In this article, an analysis will be made of the re-invention of the popular urban cultural circuits and the direct mediation of contemporary media practice. Specifically evident was the use of technological communication devices as the means of constituting contemporary popular Brazilian urban cultures. Based on the documentary 100\% Favela, produced in Brazil, there is an emphasis, within social practice, on the self-management of the cultural and communicational processes as a form of re-invention of the means of economic and symbolic existence in a favela (shanty town) in the city of São Paulo. The use of the media devices and the construction of self-dialogue within this outer-city culture requires, these days, new modes of social listening.

\section{Keywords}

Communication. Documentary. Popular culture.

Mediation.
En este artículo se analiza la reinvención de los circuitos culturales populares urbanos en interacción directa con las prácticas comunicativas contemporáneas. Destaque específico para el uso de los dispositivos tecnológicos de la comunicación como modo de constitución de las culturas urbanas brasileñas de la contemporaneidad. Tomando como referencia el documental 100\% Favela, de procedencia nacional, de entre las prácticas sociales, el énfasis recae sobre la autogestión de los procesos comunicativos y culturales como modificadores de los modos de existir económico y simbolicamente en una favela de la ciudad de São Paulo. El uso de los dispositivos comunicativos y la construcción de la periferia actualmente demandan nuevas formas de escucha social.

\section{Palabras clave}

Comunicación. Documental. Culturas populares. Mediaciones. 


\section{Expediente}

A revista E-Compós é a publicação científica em formato eletrônico da Associação Nacional dos Programas de Pós-Graduação em Comunicação (Compós). Lançada em 2004, tem como principal finalidade difundir a produção acadêmica de pesquisadores da área de Comunicação, inseridos em instituições do Brasil e do exterior.
E-COMPÓS I www.e-compos.org.br I E-ISSN 1808-2599

Revista da Associação Nacional dos Programas de Pós-Graduação em Comunicação. Brasília, v.11, n.1, jan./abr. 2008.

A identificação das edições, a partir de 2008, passa a ser volume anual com três números.

\section{CONSELHO EDITORIAL}

\section{Afonso Albuquerque}

Universidade Federal Fluminense, Brasil

Alberto Carlos Augusto Klein

Universidade Estadual de Londrina, Brasi

Alex Fernando Teixeira Primo

Universidade Federal do Rio Grande do Sul, Brasi

Alfredo Vizeu

Universidade Federal de Pernambuco, Brasil

Ana Carolina Damboriarena Escosteguy

Pontifícia Universidade Católica do Rio Grande do Sul, Brasil

Ana Silvia Lopes Davi Médola

Universidade Estadual Paulista, Brasil

André Luiz Martins Lemos

Universidade Federal da Bahia, Brasil

Ângela Freire Prysthon

Universidade Federal de Pernambuco, Brasil

Antônio Fausto Neto

Universidade do Vale do Rio dos Sinos, Brasil

Antonio Carlos Hohlfeldt

Pontifícia Universidade Católica do Rio Grande do Sul, Brasil

Arlindo Ribeiro Machado

Universidade de São Paulo, Brasil

César Geraldo Guimarães

Universidade Federal de Minas Gerais, Brasi

Cristiane Freitas Gutfreind

Pontifícia Universidade Católica do Rio Grande do Sul, Brasil

Denilson Lopes

Universidade Federal do Rio de Janeiro, Brasil

Eduardo Peñuela Cañizal

Universidade Paulista, Brasil

Erick Felinto de Oliveira

Universidade do Estado do Rio de Janeiro, Brasil

Francisco Menezes Martins

Universidade Tuiuti do Paraná, Brasil

Gelson Santana

Universidade Anhembi/Morumbi, Brasil

Hector Ospina

Universidad de Manizales, Colômbia

leda Tucherman

Universidade Federal do Rio de Janeiro, Brasil

Itania Maria Mota Gomes

Universidade Federal da Bahia, Brasil

Janice Caiafa

Universidade Federal do Rio de Janeiro, Brasil

Jeder Silveira Janotti Junior

Universidade Federal da Bahia, Brasil
John DH Downing

University of Texas at Austin, Estados Unidos

José Luiz Aidar Prado

Pontifícia Universidade Católica de São Paulo, Brasil

José Luiz Warren Jardim Gomes Braga

Universidade do Vale do Rio dos Sinos, Brasi

Juremir Machado da Silva

Pontifícia Universidade Católica do Rio Grande do Sul, Brasil

Lorraine Leu

University of Bristol, Grã-Bretanha

Luiz Claudio Martino

Universidade de Brasília, Brasil

Maria Immacolata Vassallo de Lopes

Universidade de São Paulo, Brasil

Maria Lucia Santaella

Pontifícia Universidade Católica de São Paulo, Brasil

Mauro Pereira Porto

Tulane University, Estados Unidos

Muniz Sodre de Araujo Cabral

Universidade Federal do Rio de Janeiro, Brasil

Nilda Aparecida Jacks

Universidade Federal do Rio Grande do Sul, Brasil

Paulo Roberto Gibaldi Vaz

Universidade Federal do Rio de Janeiro, Brasil

Renato Cordeiro Gomes

Pontifícia Universidade Católica do Rio de Janeiro, Brasil

Ronaldo George Helal

Universidade do Estado do Rio de Janeiro, Brasil

Rosana de Lima Soares

Universidade de São Paulo, Brasil

Rossana Reguillo

Instituto Tecnológico y de Estudios Superiores do Occidente, México

Rousiley Celi Moreira Maia

Universidade Federal de Minas Gerais, Brasil

Sebastião Carlos de Morais Squirra

Universidade Metodista de São Paulo, Brasil

Simone Maria Andrade Pereira de Sá

Universidade Federal Fluminense, Brasil

Suzete Venturelli

Universidade de Brasília, Brasil

Valério Cruz Brittos

Universidade do Vale do Rio dos Sinos, Brasil

Veneza Mayora Ronsini

Universidade Federal de Santa Maria, Brasil

Vera Regina Veiga França

Universidade Federal de Minas Gerais, Brasil

\section{COMISSÃO EDITORIAL}

Ana Gruszynski I Universidade Federal do Rio Grande do Sul, Brasil João Freire Filho I Universidade Federal do Rio de Janeiro, Brasil Rose Melo Rocha I Escola Superior de Propaganda e Marketing, Brasil

\section{CONSULTORES AD HOC}

Bianca Freire-Medeiros I Fundação Getulio Vargas, Brasil Josimey Costa da Silva I Universidade Federal do Rio Grande do Norte, Brasil Maria Conceição Golobovante I Pontifícia Universidade Católica de São Paulo, Brasil Marlyvan Moraes de Alencar I Centro Universitário SENAC-SP, Brasil Miriam de Souza Rossini I Universidade Federal do Rio Grande do Sul, Brasil Paulo Ribeiro I Pontifícia Universidade Católica do Rio de Janeiro, Brasil Rita Alves de Oliveira I Centro Universitário SENAC, Brasil

REVISÃO DE TEXTO E TRADUÇÃO I Everton Cardoso ASSISTÊNCIA EDITORIAL E EDITORAÇÃO ELETRÔNICA I Raquel Castedo
COMPóS I www.compos.org.br

Associação Nacional dos Programas de Pós-Graduação em Comunicação

Presidente

Erick Felinto de Oliveira

Universidade do Estado do Rio de Janeiro, Brasil erickfelinto@uol.com.br

Vice-presidente

Ana Silvia Lopes Davi Médola

Universidade Estadual Paulista, Brasil

asilvia@faac.unesp.br

Secretária-Geral

Denize Correa Araújo

Universidade Tuiuti do Paraná, Brasil

denizearaujo@hotmail.com 